\title{
ANALYSIS OF MORBIDITY RATE OF THE POPULATION AT THE ARCTIC TERRITORIES ON THE EXTENT OF COMMERCIAL DEVELOPMENT AND ECOLOGICAL STATE ON THE EXAMPLE OF KRASNOYARSK KRAI
}

\author{
Dr. Anna Semenova \\ Dr. Irina Popelnickaya \\ Prof. Dr. Eugenia Buharova \\ Prof. Dr. Veronica Razumovskaya \\ Dr. Anatoly Buharov \\ Siberian Federal University, Russia
}

\begin{abstract}
The traditional natural resource management of the Arctic regions increases the risks of ecological safety of the northern territories and indigenous peoples. The goal of the research is to determine the impact of inefficient nature management on the population of Arctic zone by the example of Krasnoyarsk Krai northern areas.

A panel data analysis has been selected as the research methodology which integrates the possibilities for both time-series analysis and spatial observations allowing considering individual heterogeneity of observation units and the opportunity to investigate the dynamics pattern of the individual characteristics of statistical units, to design and test more complicated behavioral models and avoid bias in data aggregation. A unified initial sampling was taken for the research which observation units are the city districts and municipalities of the Arctic zone of Krasnoyarsk Krai for the period 2007 to 2014 with a possibility to replenish panel data.
\end{abstract}

The dependent variable for designing multiple linear regressions for the selected panel data is based on the population morbidity indicator; the variables describing economic and social spheres and the parameters describing the level of the ecological state of the investigated areas were used as endogenous factors. The model designed as the research result showed the presence of lagged relationships between the health of population living in the Arctic zone of the Krasnoyarsk Krai and the level of its commercial development. The research results can be used for determination of the responsibility of regional and federal authorities for consequences of ineffective nature management on the sensitive Arctic territories.

Keywords: panel studies, ecological risks, morbidity, economic growth, multivariate regression, the Arctic zone of Krasnoyarsk Krai

\section{INTRODUCTION}

Since 2000 on the basis of Siberian Federal University in Krasnoyarsk Krai the researches on socio-economic and ecologic conditions of the municipal entities of this 
region have been conducted. Collection and systematization of the information on cities and districts comprising the Krai allow forming a panel data to observe tendencies in the development and transformation of economic, social and ecologic processes diachronically.

For this study from the whole data panel we have chosen 4 municipal entities which enter the Arctic Zone, i.e. Norilsk city; Taymyrskiy, Turukhanskiy and Evenkiyskiy municipal districts. They all cover $3 / 4$ of Krasnoyarsk Krai and their population is less than $10 \%$ from the regionwide figure. At the same time, the share of industrial production for these entities is more than $50 \%$ from the all-region indicators. Besides, on the amount of contaminated elements emitted from the stationary sources that have adverse impacts on the public health and environment the Territory enters the 5 -worst regions of Russia. The contribution of the Northen Regions into the regionwide emissions has increased from 1.5 times in 2007 to 6.2 times in 2015.

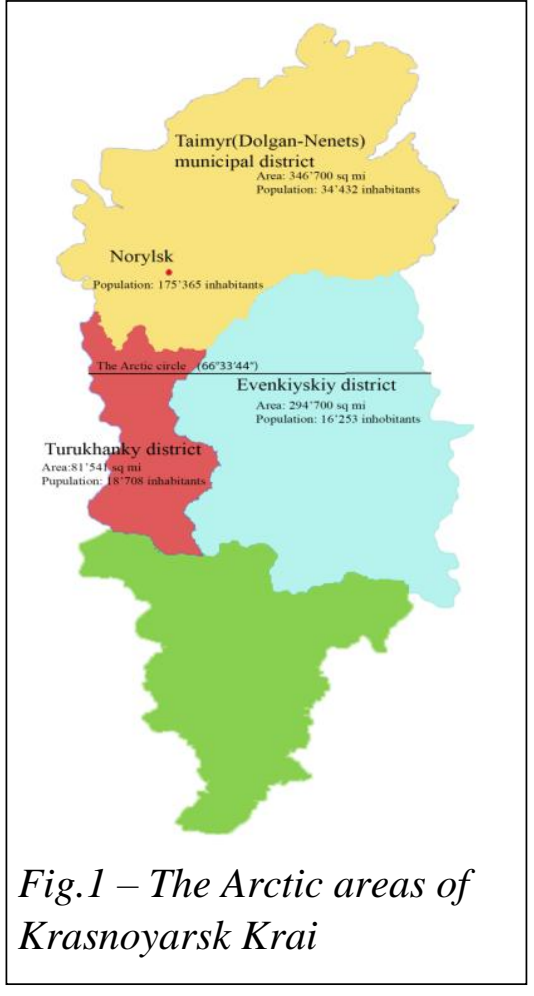
During the same period the morbidity rate has grown in 1.3 times in relation to the regionwide indicators.

The focus on these Arctic areas is determined by a disproportion of the current socioeconomic and ecologic condition. The high level of natural resources endowment of the Arctic mainland and ice sheet demands the necessity of active industrial exploration that considerably puts further stress on the vulnerability and fragility of the Arctic ecosystems, including the health of its inhabitants. A possibility of negative impacts on the public health caused by anthropogenic factors requires a detailed investigation indicating the most important affecting factors that further would allow identifying the development strategies appropriate to the Arctic regions; forming public regional programs based on the creation of proper conditions for innovations, investments and efficient implementation of the first-order competitive advantages which may lead to the emergence of new sources of compatibility with eco-systems in the Arctic areas. One of the most significant impact factors is atmospheric pollution - the most aggressive environment influencing all the parts of biota and humans [1].

\section{MATERIALS AND METHODS}

To conduct the research we have set a database representing the panel information on the municipal districts of Krasnoyarsk Krai of Russia, containing a wide range of indicators related to different spheres of economy, social sector and ecology. It serves as a good framework for the empirical analyses of the socio-economic models for the development of regions, particularly of the resource ones. The important feature of this panel is the nature of data which allow using lagged variables and controlling constant non-observable individual characteristics.

The study exploits the panel data comprised of repeated observations of one and the same unities of the set (4 municipal entities of the Arctic Zone of Krasnoyarsk Krai, 
which were sequentially conducted between 2007 and 2014 with the use of the united methodological system and data analyses procedure on 59 economic, social and ecologic indicators. Thus, the economic indicators unit contains 17 variables among which Var1 - "Amount of shipped own-produced goods, works and services made inhouse", ths rub; Var2 - "Share of industrial production in the whole amount of shipped goods output", \%; Var 3 - "Share of the annual average number of employed people within the resident population",\% Var4 - "Workforce efficiency", ths rub per capita; Var5 - "Investments into the basic capital per capita", mln rub; Var6 - "Fixed assets", mln rub; Var11 - "Capital/labor ratio", ths rub per capita; The social unit includes 26 indicators, e.g.: Var 23 - Living space per capita; Var 25 - Unemployment rate within the total population, \%; Var 48 - Doctors availability, doctors per 10000 people. The ecologic unit consists of 16 variables including: Var33 - Morbidity rate (registered primary disease incidents: per 1000 inhabitants); Var34 - Total morbidity rate (per 1000 inhabitants); Var36 - Emissions made by stationary sources on $1 \mathrm{~km}^{2}$ of built-up land, $\mathrm{tn} / \mathrm{km}^{2}$.

The choice for panel data has been made due to the fact that it possesses an opportunity to analyze both time series and space observations. Besides, it is possible to consider and analyze specific differences between the economic unities what cannot be done within standard regression models which enable to evaluate the power of coherence between them. The use of panel data also gives an opportunity to include a specific heterogeneity of the observation units; allow exploring the dynamics of changes in the features of combination units. "Panels" are better able to identify and measure the effects not defined within only the time-series or spatial data; provide constructing and testing more complex behavior models and avoid bias caused by aggregation of the data [2].

The advantages of longitudinal studies are not limited only by the opportunity to track the development of municipal entities. The longitudinal research can be especially efficient for monitoring continuous, gradual transformations happening to the municipal entities in terms of deliberately existing asymmetry in the development of socioeconomic situation in different territories.

The variables values on the observation in longitude have been taken from the official sites of the Federal State Statistics Service of the Russian Federation and the Federal State Statistics Service of Krasnoyarsk Krai, as well as from the official web-sites of the Ministry of Healthcare of Krasnoyarsk Krai and the Ministry of Natural Resources and Ecology of Krasnoyarsk Krai.

\section{RESULTS}

The environmental condition is one of the factors influencing the public health. According to the medical researches commissioned by the Ministry of Healthcare and Social Policy of Krasnoyarsk Krai, there is a link between the adverse state of the atmosphere and morbidity of the population in general, and particularly between increasing incidents of respiratory diseases [3].

Depreciation of the air quality can be considered as negative investments into the healthcare that, in turn, may impact the social sphere and regional economy. 
The initial phase of the study is focused on the assessment of the power and type of correlation between the morbidity and emissions volume. For the entire number of observations a linear dependence between these factors has been identified, yet those found coherence coefficients are considerable, but the link power and its vectors are different for the municipal entities. As the example of such obtained linear correlation models we will bring the data on Norilsk (see Fig. 2). Regarding other territories, there are the same

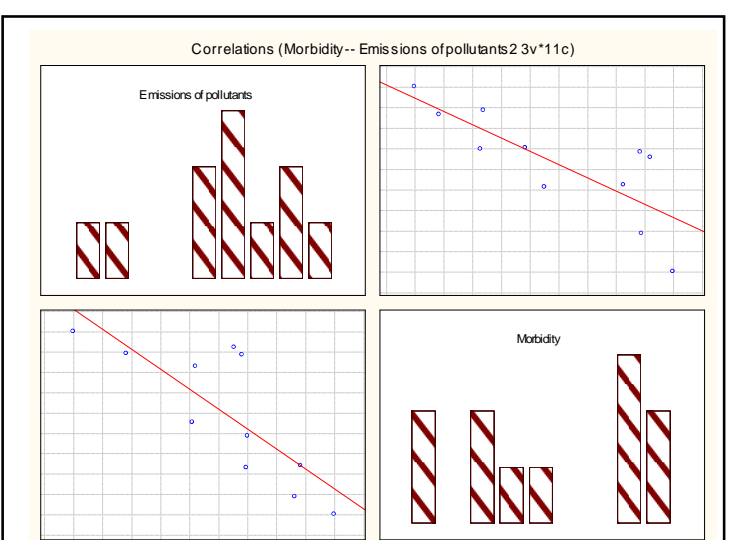

Fig. 2 - Correlograms on Norilsk dependences. This correlation-regression analysis of the relation between the gross emissions and the rate of respiratory diseases and total morbidity level as well as the primary disease incidents has demonstrated the different nature of the correlation within the analyzed districts of the Arctic Zone of Krasnoyarsk Krai and has enabled determining the linear regression equations for all the areas of the Arctic Zone of Krasnoyarsk Krai.

The greatest deviations and lowest correlation between the gross emissions and total number of diseases, of respiratory diseases and primary disease incidents can be observed in the Taimyr (Dolgano-Nenetskiy) Municipal District which has been marked with a high morbidity rate given relatively small amount of emissions (see Fig.3).

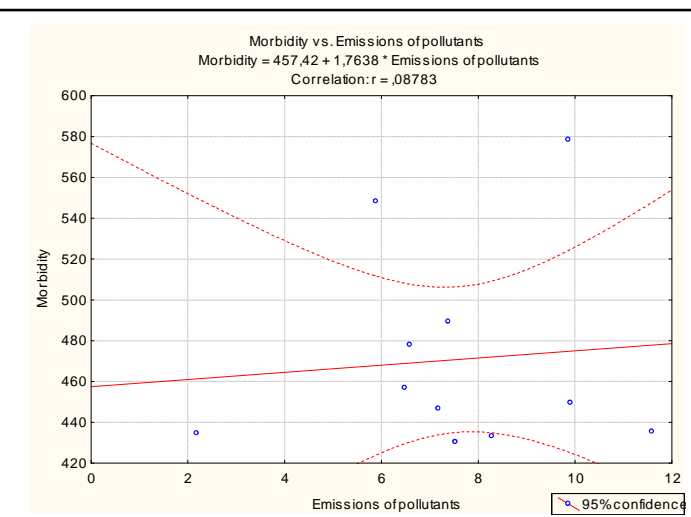

Taimyr (Dolgano-Nenetskiy) Municipal District

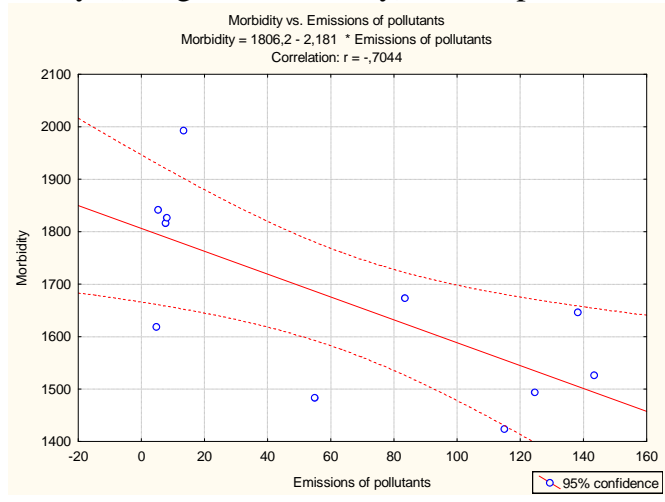

Turukhansk Municipal District

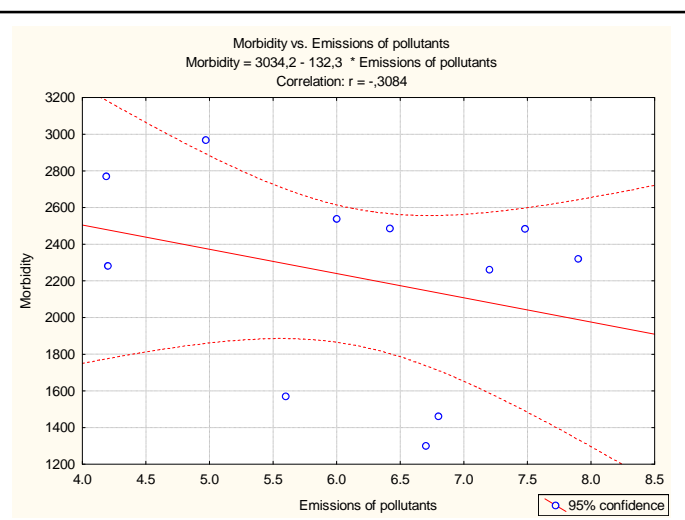

Evenk Municipal District

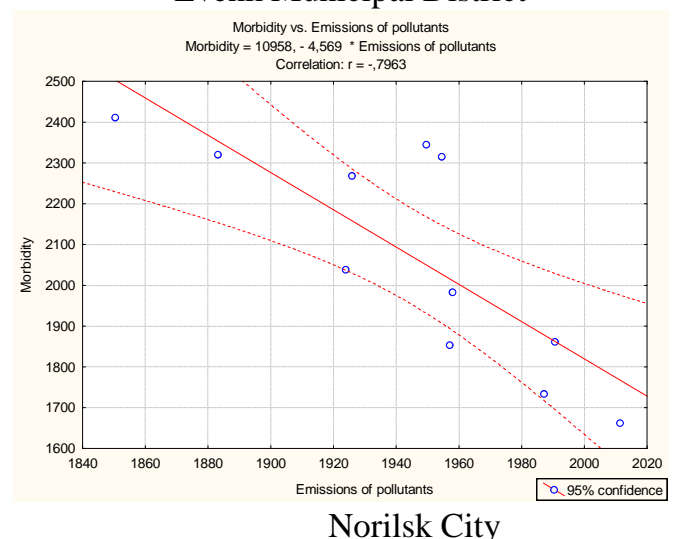

Norilsk City

Fig. 3 -Regression models on the municipal entities 
Considering the Evenk Municipal District one can note an average and statistically reliable link between the above mentioned parameters. The Turukhansk Municipal District has a close and prominent correlation between the emissions and number of diseases. The highest correlation coefficient (a strong negative relation) has been observed in Norilsk (see Fig.3).

The lowest figures of the correlation have been found in those territories which have insignificant amounts of emissions with a weak tendency towards increase. In the districts with an intensive economic exploration we have revealed a negative pattern of the correlations: reduction in the emissions rate does not lead to decrease in the morbidity level that, presumably, can be explained by the accumulation of pollutants in the human organism and impossibility to allocate indigenous population among the whole group of residents. All the examined areas have been marked with a firm tendency to a growing number of respiratory and cardiovascular diseases in relation to the total morbidity rate. Given the increase in economic growth on the territories, the reduction of disease cases can be reasoned by attracting additional labor force to work on rotating basis.

The close correlation between the emissions and morbidity has been discovered in the Turukhansk Municipal District (7.5\% of the all-region emissions volume) and in Norilsk ( $75 \%$ of the all-region emissions volume) that allows forming a hypothesis on a dependence of the morbidity rate on the level of industrial development of the territory.

To verify this hypothesis we have used a method of multiple regression construction which includes the economic and social indicators. In this regard, during the initial stage of the regression equation formation we have switched to logarithms for the selected factors ${ }^{1}$ which have made it possible to diminish the asymmetry of the econometric values distribution and approximate the distribution of regression residuals towards normal [4 -5].

The research has provided with a pooled regression model of the total morbidity rate (lvar34).

\begin{tabular}{|c|c|c|c|c|c|c|}
\hline Source & ss & $d f$ & MS & & $\begin{array}{l}\text { Number of obs } \\
\mathrm{F}(5,26)\end{array}$ & $\begin{array}{rr}= & 32 \\
= & 29.84\end{array}$ \\
\hline Model & 1.04301591 & $.2 C$ & \multirow{2}{*}{$\begin{array}{r}.208603181 \\
.00699007\end{array}$} & & Prob > F & $=0.0000$ \\
\hline Residual & .181741812 & 26 & & & R-squared & $=0.8516$ \\
\hline Total & 1.22475772 & $31 \quad .03$ & .039508314 & & Root MSE & $=.08361$ \\
\hline $1 \operatorname{var} 34$ & Coef. & Std. Err. & t & $P>|t|$ & [95\% Conf. & Interval] \\
\hline lvar5 & .1634326 & .0227885 & 7.17 & 0.000 & .1165902 & .2102751 \\
\hline $1 \operatorname{var} 23$ & .7768449 & .096653 & 8.04 & 0.000 & .5781718 & .975518 \\
\hline 1 var25 & .120813 & .0537651 & 2.25 & 0.033 & .0102972 & .2313288 \\
\hline $1 \operatorname{var} 36$ & -.1331835 & .0147564 & -9.03 & 0.000 & -.1635157 & -.1028513 \\
\hline $1 \operatorname{var} 48$ & .4363598 & .0448262 & 9.73 & 0.000 & .3442182 & .5285015 \\
\hline cons & 1.55039 & 5383284 & 2.88 & 0.008 & .4438405 & 2.65694 \\
\hline
\end{tabular}

\footnotetext{
${ }^{1}$ lvar* $=\log \left(\operatorname{var}^{*}\right)$, where $*$ means the number of the research panel's variable
} 
As it turned out, according to the results of calculation, the total morbidity of the Northern Areas of Krasnoyarsk Krai depends on 5 parameters: "Investments into the basic capital per capita" (lvar5), Living space per capita (lvar23), Unemployment rate within the total population (lvar25), Emissions made by stationary sources on $1 \mathrm{~km}^{2}$ of built-up land (lvar36), doctors availability (lvar48) (see Fig.4).

It is worth noting that the pooled regression constructed through all the years and research objects does not take into consideration the panel structure of the data. Still, even then, there is the dependence of the morbidity on growing investments into the basic capital as well as increasing emissions made by the stationary sources that, in turn, proves the hypothesis on rise in the morbidity rate caused by the degree of industrial development of the territories.

Quite logically in this model, together with the growth of unemployment rate within the total population (at-risk group increase), the total morbidity will also enhance.

The model of pooled regression for primary disease incidents looks quite different (lvar33). In this case the model has included such indicators as the amount of shipped own-produced goods, works and services made in-house (lvar1), fiscal revenue of the municipal entity per capita (lvar32) (see Fig.5).

The Northern Areas of Krasnoyarsk Krai are mainly characterized by the resource development. The increase in production (lvar1) and the regional budget increase (lvar32) mean an upturn of the industrial development, increased extraction of mineral resources and their primary processing and, consequently, rising negative impact on the Arctic ecology and residents.

\begin{tabular}{|c|c|c|c|c|c|c|c|}
\hline Source & SS & $d f$ & \multicolumn{2}{|c|}{ MS } & & \multirow{2}{*}{$\begin{array}{l}\text { Number of obs } \\
\text { F( 3, 28) } \\
\text { Prob > F }\end{array}$} & \multirow{2}{*}{$\begin{array}{rr}= & 32 \\
= & 13.42 \\
& =0.0000\end{array}$} \\
\hline Model & .99343535 & 3 & \multicolumn{2}{|c|}{.331145117} & & & \\
\hline Residual & .691099736 & 28 & \multicolumn{2}{|c|}{.024682133} & & \multirow{2}{*}{$\begin{array}{l}\text { R-squared } \\
\text { Adj R-squared }=\end{array}$} & $=0.5897$ \\
\hline & & & & & & & $=0.5458$ \\
\hline Total & 1.68453509 & 31 & \multicolumn{2}{|c|}{.054339842} & & Root MSE & $=.15711$ \\
\hline $1 \operatorname{var} 33$ & Coef. & std. & Err. & t & $P>|t|$ & [95\% Conf. & Interval] \\
\hline Ivar1 & .1504986 & .0389 & 413 & 3.86 & 0.001 & .0707311 & .2302662 \\
\hline lvar 4 & -.2674906 & .0544 & 989 & -4.91 & 0.000 & -.3791265 & -.1558547 \\
\hline $1 \operatorname{var} 32$ & .2106344 & .0406 & $\$ 399$ & 5.18 & 0.000 & .1273873 & .2938815 \\
\hline cons & 5.38844 & .4420 & 714 & 12.19 & 0.000 & 4.482898 & 6.293983 \\
\hline
\end{tabular}

In case if we switch from the pooled regression to a regression with deterministic effects in the terms of deviations of the average time variables we will obtain the evaluation models for the total and primary morbidity (see Figs. 6-7).

The model of total morbidity with deterministic effects (see Fig.7) allowed identifying the relation with socially and economically important factors. For example, with the increased investments the level of total morbidity also increases that confirms the hypothesis on the correlation between morbidity and the economic development of the territory. 


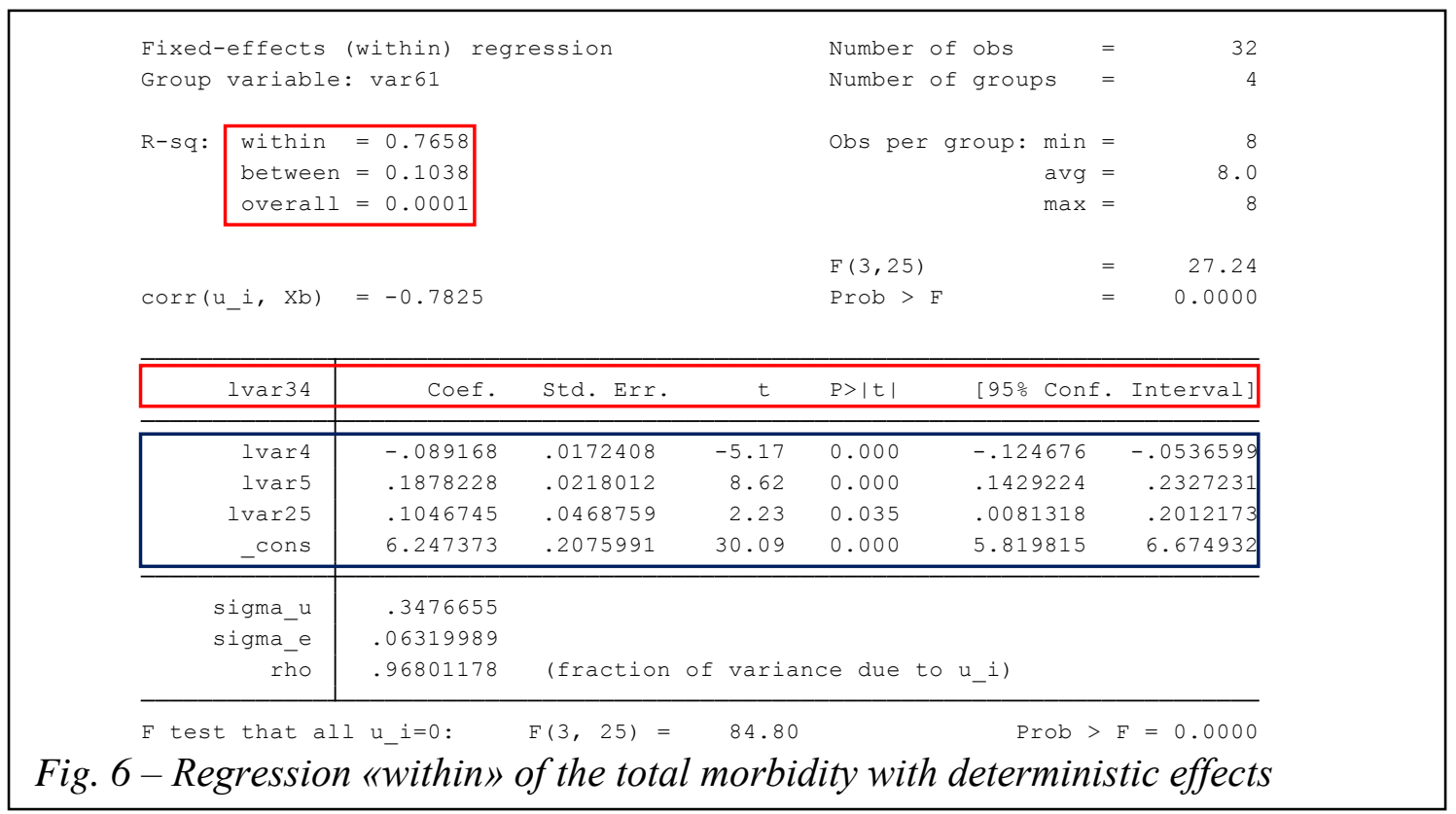

The model of primary morbidity (see Fig.7) even more so to prove this hypothesis: with the growth of output, of the share of industrial production, investments in the basic capital per capita as well as fixed assets, the primary morbidity rate also rises.

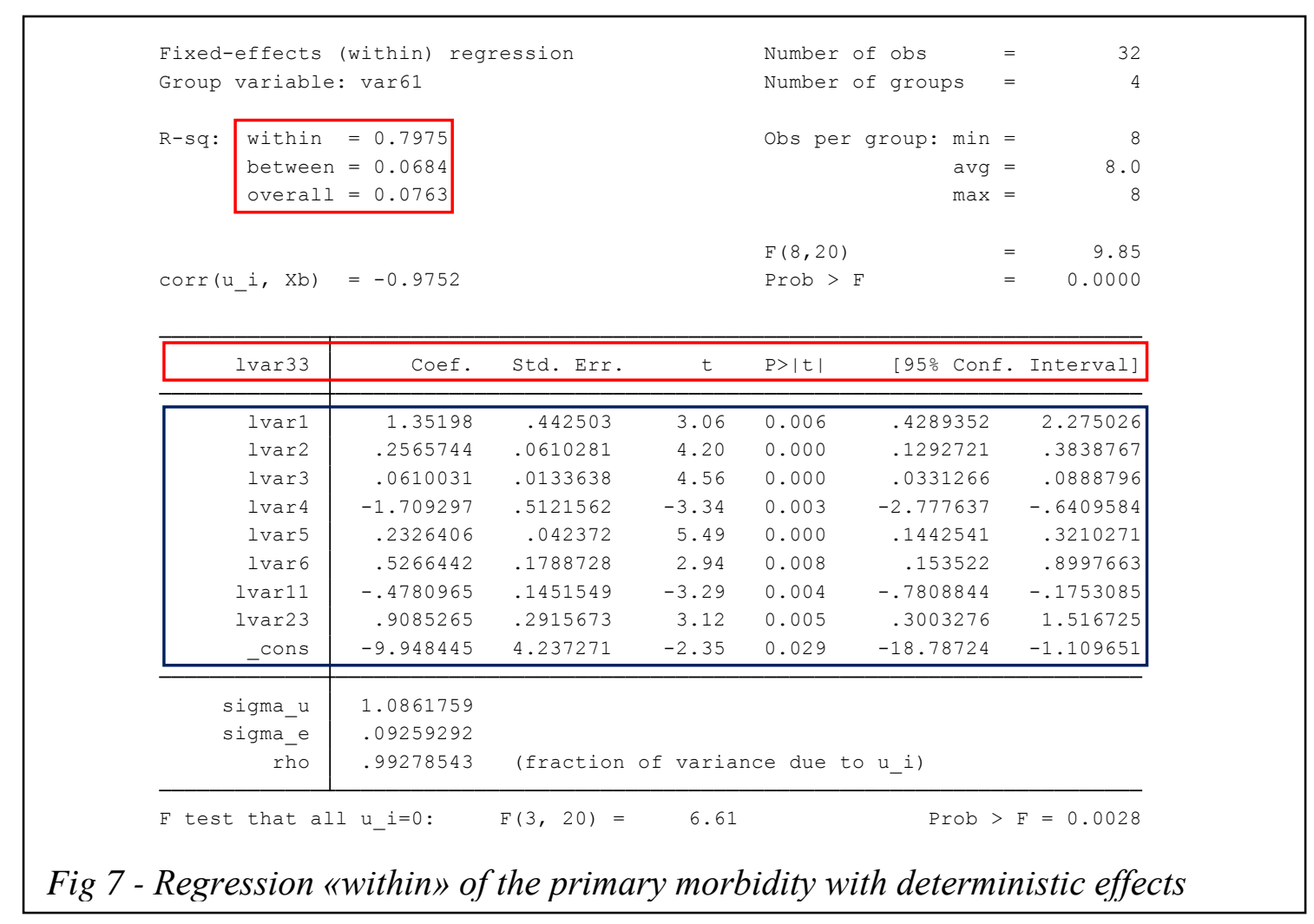

\section{CONCLUSIONS}

In this research to measure the morbidity rate indicators among the Northern Areas of Krasnoyarsk Krai we have used new methodic techniques based on the econometric 
methods which have allowed identifying the most significant economic, social and ecologic factors. The models built up within the research course have demonstrated the existence of lagging relations between the health of residents living in the Arctic Zone of Krasnoyarsk Krai and the level of its industrial development.

Thus, this very toolkit gives an opportunity to address the socio-economic phenomena and mechanisms within the space-time continuum and allows forecasting and accepting scientifically reasoned decisions in the sphere of regional policy, including the public health authorities.

\section{ACKNOWLEDGMENT}

The article is written with the financial support of RHSF and Krasnoyarsk Krai (Project "The Methodology of Modeling and Forecasting Scenarios of 'Green Economy' and the Bioeconomy of Regions in the Conditions of Active Economic Development of the Arctic Zone Resources" \# a (p) 16-12-24023)

\section{REFERENCES}

[1] Arbia G., Spatial Econometrics. Statistical Foundations and Applications to Regional Convergence, Springer, 208 p., 2006.

[2] Edward W. Frees, Longitudinal and Panel Data: Analysis and Applications in the Social sciences, Cambridge University press, 2004.

[3] Savchenkov M, Public Health and Environment, Sib. Med. Journal (Irkutsk)/issue 3, pp. 124-127, 2010.

[4] Kozyreva P, Kosolapov M., Barry M. Popkin, Data Resource Profile: The Russia Longitudinal Monitoring Survey - Higher School of Economics (RLMS-HSE) Phase II: Monitoring the Economic and Health Situation in Russia, pp. 1994-2013 Int. J. Epidemiol, 2016

[5] Nepomnyaschaya N., Semenova A., Methodological Approaches to the Formation of the Applied Models for Panel Data Analysis to Forecast the Resource Region Economic Development under Conditions of Spatial Asymmetry (Exemplified by the Krasnoyarsk Territory), Journal of Siberian Federal University. Humanities \& Social Sciences vol. 10/issue 9, pp. 2632-2639, 2016. 